\title{
Pharmacological characterization of nanoparticle- induced platelet microaggregation using quartz crystal microbalance with dissipation: comparison with light aggregometry
}

\author{
This article was published in the following Dove Press journal: \\ International Journal of Nanomedicine \\ 13 August 2015 \\ Number of times this article has been viewed
}

\author{
Maria J Santos-Martinez ${ }^{1,2, *}$ \\ Krzysztof A Tomaszewski ${ }^{1,3, *}$ \\ Carlos Medina' \\ Despina Bazou ${ }^{4}$ \\ John F Gilmer' \\ Marek W Radomski, 1,6 \\ 'School of Pharmacy and \\ Pharmaceutical Sciences and Trinity \\ Biomedical Sciences Institute, ${ }^{2}$ School \\ of Medicine, Trinity College Dublin, \\ University of Dublin, Dublin, Ireland; \\ ${ }^{3}$ Department of Anatomy, Jagiellonian \\ University Medical College, Krakow, \\ Poland; ${ }^{4}$ Edwin L Steele Laboratory, \\ Department of Radiation Oncology, \\ Massachusetts General Hospital and \\ Harvard Medical School, Boston, \\ MA, USA; ${ }^{5}$ Kardio-Med Silesia, \\ Zabrze, ${ }^{6}$ Medical University of Silesia, \\ Katowice, Poland \\ *These authors contributed equally \\ to this paper
}

Background: Engineered nanoparticles (NPs) can induce platelet activation and aggregation, but the mechanisms underlying these interactions are not well understood. This could be due in part to use of devices that study platelet function under quasi-static conditions with low sensitivity to measure platelet microaggregation. Therefore, in this study we investigated the pharmacological pathways and regulators of NP-induced platelet microaggregation under flow conditions at nanoscale using quartz crystal microbalance with dissipation (QCM-D) and compared the data thus obtained with those generated by light aggregometry.

Methods: Blood was collected from healthy volunteers, and platelet-rich plasma was obtained. Thrombin receptor-activating peptide, a potent stimulator of platelet function, and pharmacological inhibitors were used to modulate platelet microaggregation in the presence/absence of silica (10 $\mathrm{nm}$ and $50 \mathrm{~nm}$ ) and polystyrene $(23 \mathrm{~nm}) \mathrm{NPs}$. Light aggregometry was used to study platelet aggregation in macroscale. Optical, immunofluorescence, and scanning electron microscopy were also used to visualize platelet aggregates.

Results: Platelet microaggregation was enhanced by thrombin receptor-activating peptide, whereas prostacyclin, nitric oxide donors, acetylsalicylic acid, and phenanthroline, but not adenosine diphosphate (ADP) blockers, were able to inhibit platelet microaggregation. NPs caused platelet microaggregation, an effect not detectable by light aggregometry. NP-induced microaggregation was attenuated by platelet inhibitors.

Conclusion: NP-induced platelet microaggregation appears to involve classical proaggregatory pathways (thromboxane $\mathrm{A}_{2}$-mediated and matrix metalloproteinase-2-mediated) and can be regulated by endogenous (prostacyclin) and pharmacological (acetylsalicylic acid, phenanthroline, and nitric oxide donors) inhibitors of platelet function. Quartz crystal microbalance with dissipation, but not light aggregometry, is an appropriate method for studying NP-induced microaggregation.

Keywords: platelet microaggregation, quartz crystal microbalance with dissipation, pharmacology, nanoparticles

\section{Introduction}

Engineered nanoparticles (NPs) are being increasingly used in industry as well as in medical diagnostics and drug delivery systems, resulting in human exposure. ${ }^{1}$ Accidental contact during production or use of NPs is likely to happen via different routes, such as ingestion, skin penetration, or inhalation. NPs could also potentially be deliberately introduced into circulating blood during proposed medical applications. ${ }^{2}$ Once in the bloodstream, NPs come into contact with a number of blood components, including
Correspondence: Carlos Medina

School of Pharmacy and Pharmaceutical Sciences, Panoz Institute, Trinity College Dublin, Dublin 2, Ireland

Tel +353 I 8962823

Fax +353 । 8963367

Email carlos.medina@tcd.ie 
platelets. Platelets have long been known to play a key role in vascular hemostasis, and their participation in the pathogenesis of inflammation and thrombotic events such as myocardial infarction and stroke is also well documented. ${ }^{3-5}$ Indeed, several antiplatelet drugs, such as acetylsalicylic acid (ASA) and adenosine diphosphate (ADP) receptor antagonists, have been used to inhibit platelet activation in vascular diseases associated with platelet dysfunction. ${ }^{6,7}$

We have previously found that exposure of platelets to engineered carbon NPs and silica NPs led to platelet aggregation, an effect that was partly modulated by certain platelet inhibitors. ${ }^{8,9}$ However, these studies were carried out under non-flow conditions, so this effect could have been underestimated. Given that use of engineered NPs is growing and humans are being increasingly exposed to these particles, their compatibility with platelets should be carefully evaluated. ${ }^{10,11}$ Hence, interactions between NPs and platelets should be tested using devices that mimic the flow conditions encountered in the human microvasculature.

We have recently developed an in vitro model to characterize flow-induced platelet microaggregation using a commercially available quartz crystal microbalance with dissipation (QCM-D) device. Using this approach, the formation of platelet microaggregates that precede the generation of larger platelet thrombi can be studied and measured in real-time in a platelet concentration-dependent, flow-dependent, and shear stress-dependent manner; even in samples containing low platelet numbers. ${ }^{12,13}$ In addition, we have recently demonstrated that NP-induced platelet aggregation can be detected using QCM-D at NP concentrations that are undetectable by flow cytometry and light transmission aggregometry, both of which are wellestablished methods for measurement of platelet activation and aggregation. ${ }^{14,15}$ Although still considered the "gold standard" for testing platelet function, light transmission aggregometry is relatively non-physiological because separated platelets are usually stirred under low shear stress and only form macroaggregates after addition of agonists, ie, conditions that do not accurately mimic platelet adhesion, activation, or aggregation in response to vessel wall damage. ${ }^{16}$

The objective of this work was to investigate whether or not this novel approach could also be used to unravel the pharmacology and platelet aggregation pathways that underlie the interactions between NPs and platelets. For this purpose, QCM-D was used as an analytical tool to monitor the effects of different platelet-modulating agents on NP-induced platelet microaggregation. Finally, we compared the data thus obtained with those acquired by light aggregometry.

\section{Materials and methods Reagents}

All reagents were purchased from Sigma-Aldrich (Dublin, Ireland) unless otherwise indicated.

\section{Characterization of NPs}

Nonporous silica spheres (10 $\mathrm{nm}$ and $50 \mathrm{~nm}$ in size) and plain polystyrene spheres (23 nm in size) were purchased from Polysciences Europe GmbH (Eppelheim, Germany).

The morphology and size of the silica NPs were confirmed by microscopy using an Orion ${ }^{\circledR}$ Plus helium ion microscope (Carl Zeiss AG, Oberkochen, Germany). ${ }^{15}$ The size of the plain $23 \mathrm{~nm}$ polystyrene NPs was validated using a Zetasizer ${ }^{\circledR}$ Nano ZS (Malvern Instruments Ltd, Malvern, UK) at $37^{\circ} \mathrm{C}$ with a DTS $1060 \mathrm{C}$ clear disposable zeta cell (Malvern Instruments). Measurements were conducted in triplicate at a concentration of $100 \mu \mathrm{g} / \mathrm{mL}$ in phosphate-buffered saline (PBS).

\section{Blood collection and platelet isolation}

Blood was collected from healthy volunteers who had not taken any drugs known to affect platelet function for at least 2 weeks prior to the study. Informed consent was obtained from the volunteers. Platelet-rich plasma (PRP) and plateletpoor plasma (PPP) were prepared from blood as previously described. ${ }^{17}$ PRP was diluted with PBS ${ }^{13-15}$ to a final concentration of 210,000 platelets/ $\mu \mathrm{L}$. PPP was used as the control. The study was approved by the Trinity College Dublin Faculty of Health Sciences Research Ethics Committee.

\section{Measurement of platelet microaggregation under flow using QCM-D}

Platelet microaggregation was measured using an $\mathrm{E}_{4}$ system (Q-Sense AB, Gothenburg, Sweden). Briefly, this system includes a chamber platform that holds four temperature-controlled and flow-controlled modules set up in parallel configuration attached to a peristaltic pump (IMS 935, Ismatec, Glattbrugg-Zurich, Switzerland). Polystyrene-coated (PC) quartz crystals with a fundamental frequency of 4.95 $\mathrm{MHz}$ were used as sensors (Q-Sense $\mathrm{AB})$. Following coating with fibrinogen $(100 \mu \mathrm{g} / \mathrm{mL})$, the crystals were mounted in the flow chamber and PRP $(210,000$ platelets $/ \mu \mathrm{L})$ was perfused at $37^{\circ} \mathrm{C}$ with a flow rate of $100 \mu \mathrm{L} / \mathrm{min}$ according to our previous studies. ${ }^{12,13}$ Platelet microaggregation was monitored in real-time by Q-Sense software $\left(\mathrm{QSoft}_{401}\right)$ and measured and analyzed as changes in frequency $f$ and 
energy dissipation $D .{ }^{12}$ PPP was used as the control. PPP was perfused at $100 \mu \mathrm{L} / \mathrm{min}$, and changes in $f$ and $D$ were monitored for up to 30 minutes. All the following experiments were performed on fibrinogen-coated PC quartz crystals.

\section{Pharmacological modulation of fibrinogen-induced platelet microaggregation}

To investigate if the device was able to detect changes in platelet microaggregation using platelet-modulating agents, the effects of thrombin receptor-activating peptide (TRAP, $25 \mu \mathrm{M}$ ) and a number of inhibitors of platelet aggregation were tested. The compounds included standard inhibitors of platelet function at maximally effective concentrations, ie, ASA $(100 \mu \mathrm{M})$, phenanthroline $(100 \mu \mathrm{M})$, apyrase $(250 \mu \mathrm{g} / \mathrm{mL}), 2$-methylthio-AMP triethylammonium salt hydrate (2-MeSAMP, $100 \mu \mathrm{M})$, $S$-nitroso-glutathione (GSNO, $100 \mu \mathrm{M})$, and $S$-nitroso$N$-acetyl-DL-penicillamine (SNAP, $100 \mu \mathrm{M}) .{ }^{18-20}$ The platelet-modulating agents were added prior to initiation of perfusion of PRP and their effects were measured for 30 minutes. The most effective inhibitors of platelet microaggregation as measured by Q-CMD were selected for further studies to evaluate their effects on NP-induced platelet microaggregation.

Additional experiments were carried out with prostacyclin $(30 \mathrm{nM})$ which was added 60 minutes after initiation of perfusion of PRP, and its ability to induce disaggregation (dissipation of platelet microaggregates) was measured for 30 minutes.

\section{Pharmacological modulation of NP-induced platelet microaggregation}

To investigate the effects of different platelet inhibitors on NP-induced platelet microaggregation, PRP suspensions were perfused through the system at a flow rate of $100 \mu \mathrm{L} / \mathrm{min}$ in the presence of vehicle or NPs at the concentrations used in previous studies, ie, $10 \mathrm{~nm}$ silica NPs $(25 \mu \mathrm{g} / \mathrm{mL})$, $50 \mathrm{~nm}$ silica NPs $(200 \mu \mathrm{g} / \mathrm{mL})$, and $23 \mathrm{~nm}$ polystyrene NPs $(100 \mu \mathrm{g} / \mathrm{mL}){ }^{9}{ }^{9} 15$ To determine if NPs could induce changes in $f$ and $D$ in the absence of platelets, PPP was used as the control. PPP was perfused at $100 \mu \mathrm{L} / \mathrm{min}$ in the presence or absence of NPs and changes in $f$ and $D$ were monitored for up to 30 minutes. For experiments with inhibitors of platelet function, the compounds were added prior to initiation of perfusion of PRP with NPs and their effects were measured for up to 30 minutes.

\section{Optical microscopy}

The formation of platelet aggregates on the crystal surface was studied using a BX51M reflection epifluorescence microscope (Olympus, Southend-on-Sea, UK). PRP samples in the presence or absence of NPs were perfused through the device in the presence or absence of modulators of platelet function for 30 minutes. Crystals were then taken for optical microscopy using a $10 \times$ objective. Photomicrographs were captured using a digital camera and Cellsense software (version 1.1).

\section{Immunofluorescence microscopy}

PRP samples were perfused through the device in the presence or absence of TRAP and ASA for 30 minutes. Afterward, the samples were incubated with fluorescein isothiocyanate-conjugated PAC-1 antibodies (BD Biosciences, Oxford, UK) for 30 minutes at room temperature in the dark. PAC-1 recognizes an epitope on the activated glycoprotein GPIIb/IIIa complex of activated platelets in live cells. The samples were then fixed with $90 \%$ ethanol, rinsed in PBS, and mounted on a glass slide with mounting medium.

Photomicrographs were captured using a fast, highresolution XM10 camera (Soft Imaging System GmbH, Münster, Germany) mounted on an Olympus BX51M reflection epifluorescence microscope. Images were processed using Cell-P software (Soft Imaging System).

\section{Scanning electron microscopy}

For scanning electron microscopy imaging, PRP samples were perfused through the device in the presence or absence of TRAP and ASA. Afterward, the samples were fixed using $2.5 \%$ glutaraldehyde for 30 minutes at $37^{\circ} \mathrm{C}$ and then dehydrated through ascending grades of ethanol $(60 \%$ for 20 minutes, $80 \%$ for 20 minutes, $90 \%$ for 20 minutes, and finally $100 \%$ for 30 minutes, repeated once). The samples were then mounted on aluminum stubs and coated with gold/palladium (10 nm coating). Formation of platelet aggregates was visualized using an Ultra Plus field emission scanning electron microscope (Carl Zeiss AG) at $5.00 \mathrm{kV}$.

\section{Platelet aggregation monitored by light aggregometry}

The ability of NPs to induce platelet aggregation was measured using a four-channel whole blood Lumi aggregometer (Chrono-Log Corporation, Havertown, PA, USA) linked to an Aggrolink data reduction system (810DR; Chrono-Log Corporation). The NPs were sonicated for 10 minutes prior to the aggregation assay. PRP samples were incubated in 
the presence of vehicle or $10 \mathrm{~nm}$ silica NPs $(25 \mu \mathrm{g} / \mathrm{mL})$, $50 \mathrm{~nm}$ silica NPs $(200 \mu \mathrm{g} / \mathrm{mL})$, or $23 \mathrm{~nm}$ polystyrene NPs $(100 \mu \mathrm{g} / \mathrm{mL})$, and their effects were recorded for 20 minutes. Collagen $(5 \mu \mathrm{g} / \mathrm{mL})$-induced platelet aggregation and stirred platelets were used as the controls.

\section{Statistical analysis}

The results are expressed as a percentage of $f$ and $D$ from the third overtone, where the maximal changes in $f$ (negative shift) and $D$ (positive shift) at 30 minutes of perfusion for the control $(210,000$ platelets $/ \mu \mathrm{L})$ are considered as $100 \% .^{12-15}$ Data from at least three independent experiments were analyzed using GraphPad Prism 5 software (GraphPad Software, La Jolla, CA, USA). All means are reported with the standard deviation. Paired Student's $t$-tests, one-way analysis of variance, and Dunnett's multiple comparisons post-test were performed as appropriate. Statistical significance was considered at $P<0.05$.

\section{Results}

\section{Perfusion of sensor crystals with PRP leads to platelet microaggregation}

In the absence of modulators of platelet function, perfusion with PRP resulted in a decrease in $f$ and an increase in $D$
(Figure 1A), indicating deposition of platelets on the sensor surface as corroborated by optical microscopy (Figure 1C). PPP was used as the control for protein deposition on the surface of the crystals (Figure 1B and D).

\section{Pharmacological modulation of platelet microaggregation using QCM-D}

PRP samples were perfused in the presence or absence of TRAP and different platelet inhibitors. TRAP enhanced $D$ after 30 minutes of perfusion (Figure 2A). A cyclooxygenase inhibitor, $\mathrm{ASA},{ }^{21,22}$ was able to inhibit platelet aggregation, reducing the changes in both $f$ and $D$ when compared with the control (Figure 2B). The effects of ASA and TRAP on platelet aggregation were also corroborated by scanning electron microscopy and immunofluorescence microscopy, as shown in Figures 3 and 4.

Phenanthroline, a matrix metalloproteinase (MMP) inhibitor that inhibits platelet activation, ${ }^{23,24}$ also reduced platelet aggregation as measured by the device $(D p=0.006$; $f \mathrm{p}=0.0014, \mathrm{n}=7$ ). In fact, in the presence of phenanthroline, smaller aggregates were observed by optical microscopy as compared with control. Neither apyrase (an ADP scavenger) ${ }^{20,25}$ nor 2-MeSAMP (a selective $\mathrm{P}_{2} \mathrm{Y}_{12}$ receptor antagonist) ${ }^{19}$ significantly affected platelet aggregation
A

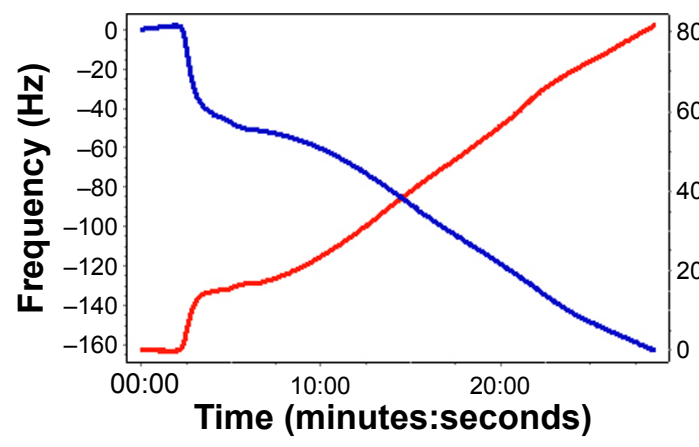

C

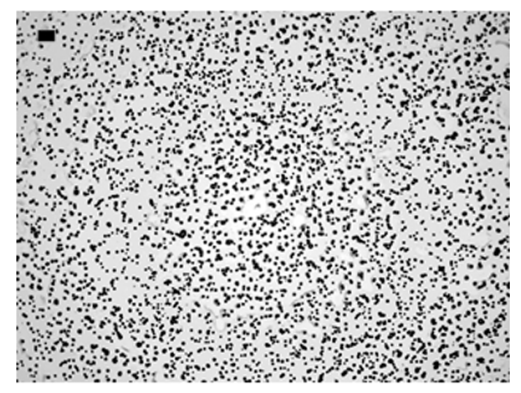

B

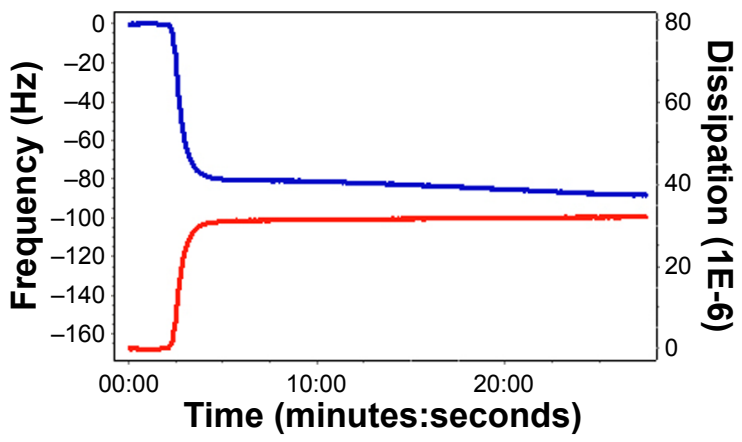

D

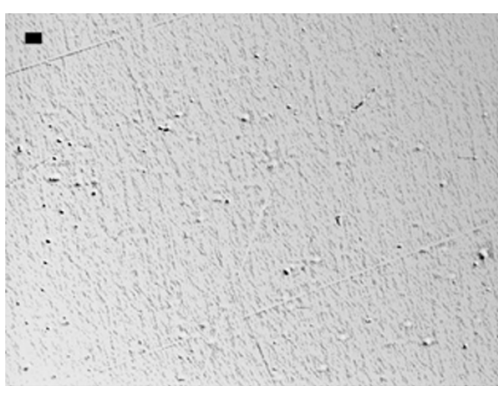

Figure I Quartz crystal microbalance with dissipation. Perfusion of PRP leads to platelet microaggregation.

Notes: (A, B) Representative traces for frequency $f$ and energy dissipation $D$ (from the third overtone) recorded by the device. Frequency is represented as a blue line and its values shown in the left axis. Energy dissipation is represented as a red line and its values are shown in the right axis. Perfusion of fibrinogen-coated polystyrene-coated quartz crystals with PRP results in platelet deposition as shown by changes in $D(80)$ and $f(-160)$. In contrast, perfusion with PPP leads to lower changes in $D(35)$ and $f(-80)$, reflecting protein deposition. (C, D) Representative micrographs of the surface of fibrinogen-coated polystyrene-coated quartz crystals as viewed by optical microscopy showing accumulation of platelet microaggregates following perfusion with PRP, but not with PPP. Scale bar $20 \mu \mathrm{m}$.

Abbreviations: PRP, platelet-rich plasma; PPP, platelet-poor plasma. 
A
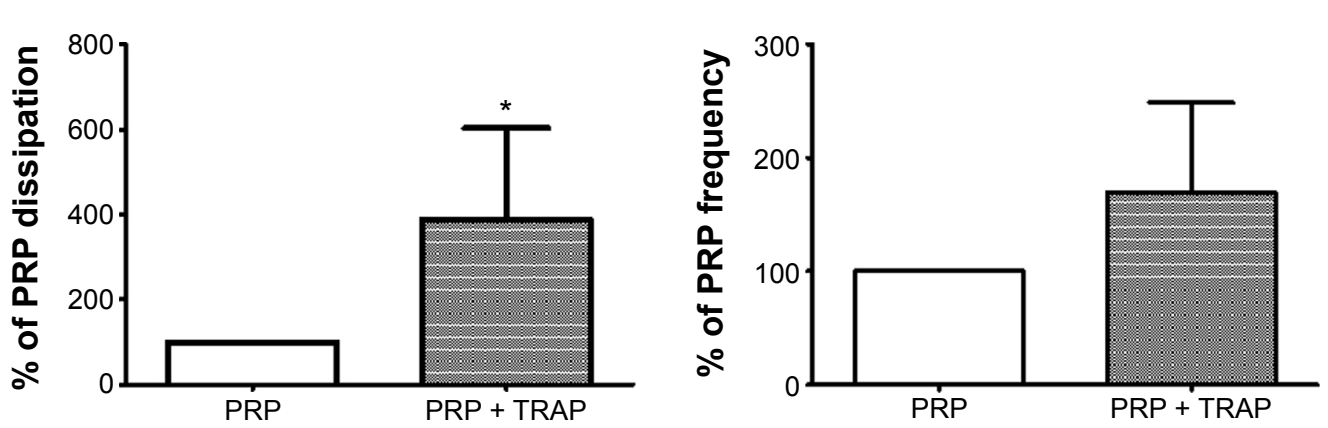

B
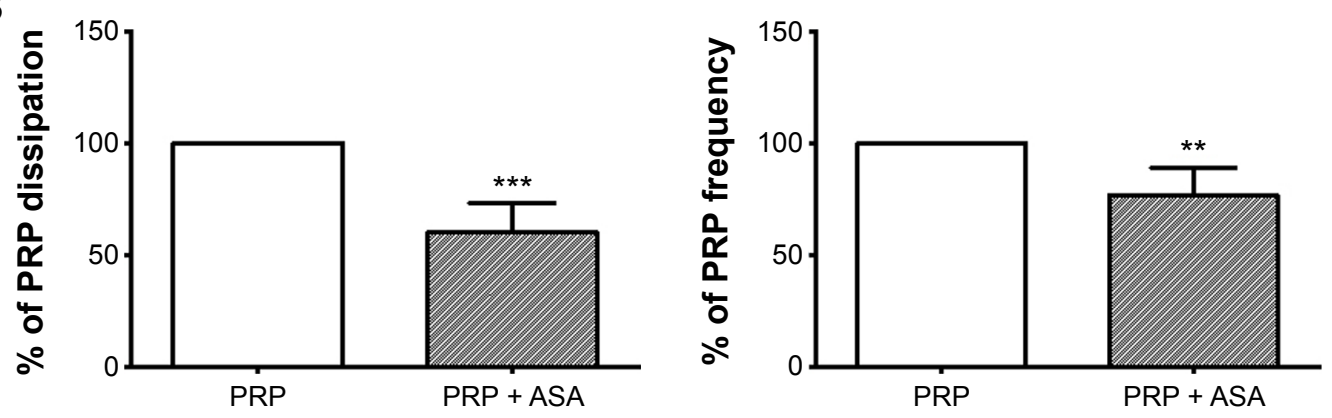

Figure 2 Quartz crystal microbalance with dissipation. Effects of TRAP and ASA on platelet microaggregation.

Notes: (A) Quantitative analysis of the effects of TRAP on frequency $f$ and energy dissipation $D$. TRAP did not significantly change $f$ but increased $D$ compared with the control. The data are presented as the mean \pm standard deviation. $* P<0.05$ versus control. (B) Quantitative analysis of the effects of ASA on frequency $f$ and energy dissipation $D$. ASA significantly changed $f$ and $D$ compared to control. The data are presented as the mean \pm standard deviation. $* P<0.05, * * P<0.0$ I, $* * * P<0.00 \mathrm{I}$ versus control. Abbreviations: ASA, acetylsalicylic acid; PRP, platelet-rich plasma; TRAP, thrombin receptor-activating peptide.
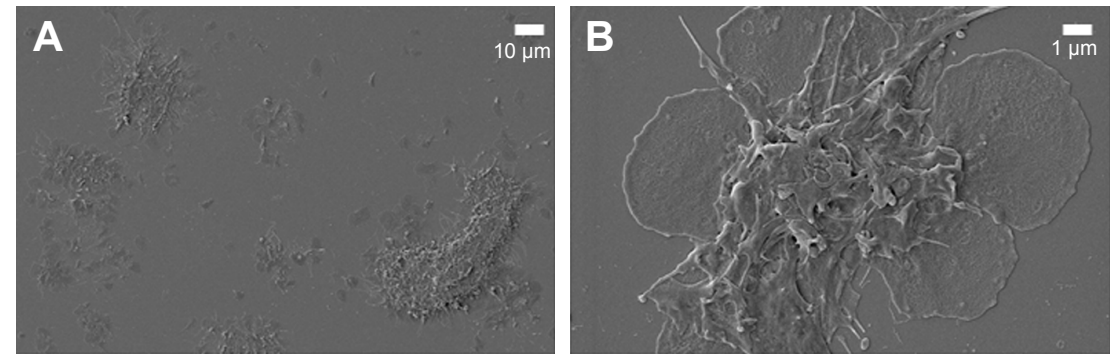

\section{Control-PRP}
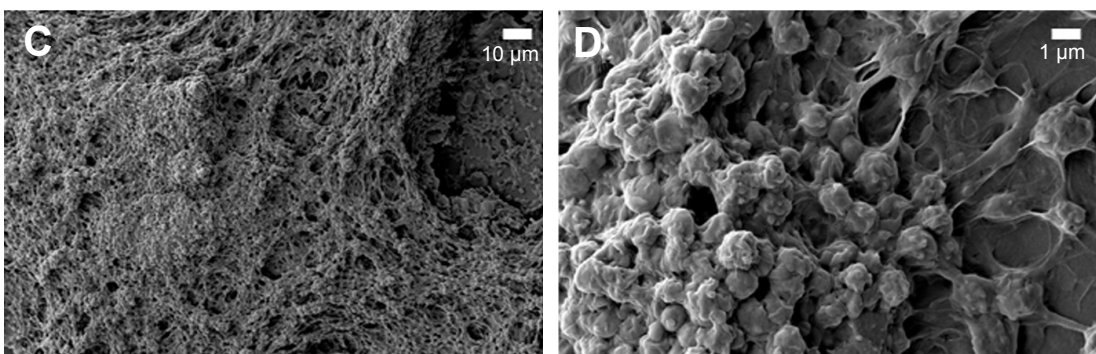

\section{PRP + TRAP}
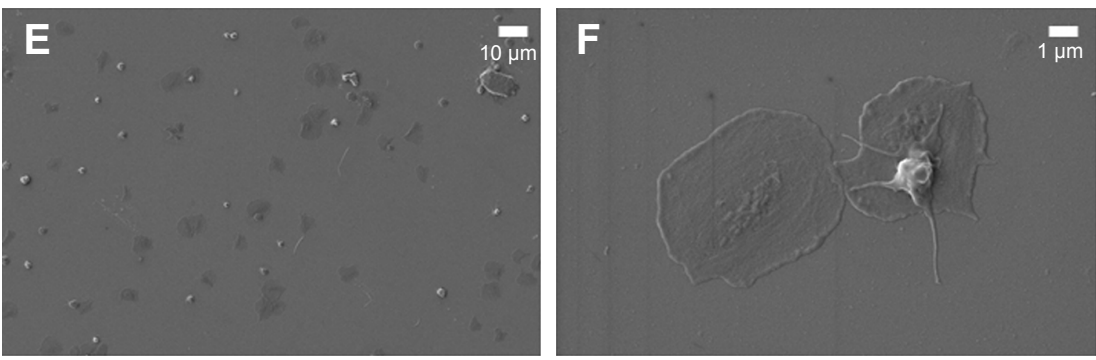

PRP + ASA

Figure 3 Scanning electron microscopy. Effects of TRAP and ASA on platelet aggregation.

Notes: (A, B) Platelet microaggregates in the absence of any pharmacological agent as imaged by scanning electron microscopy. (C, D) Platelet microaggregates in the presence of TRAP. (E, F) Platelet microaggregates in the presence of ASA.

Abbreviations: ASA, acetylsalicylic acid; PRP, platelet-rich plasma; TRAP, thrombin receptor-activating peptide. 

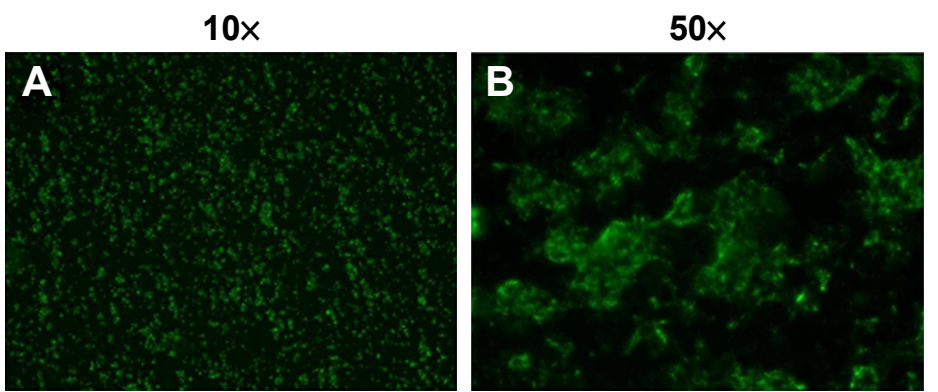

\section{Control-PRP}
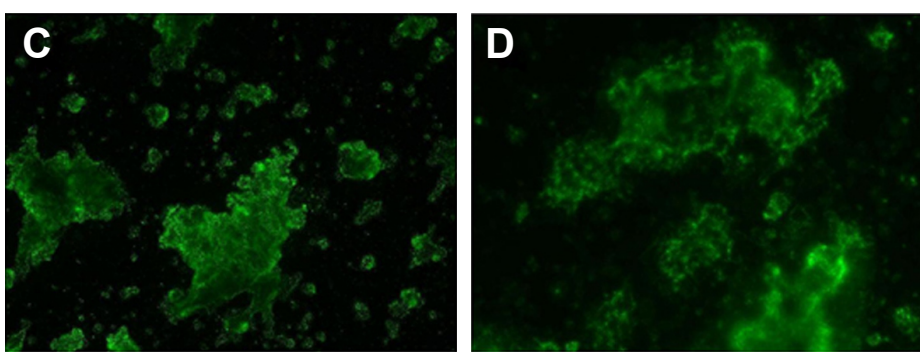

PRP + TRAP
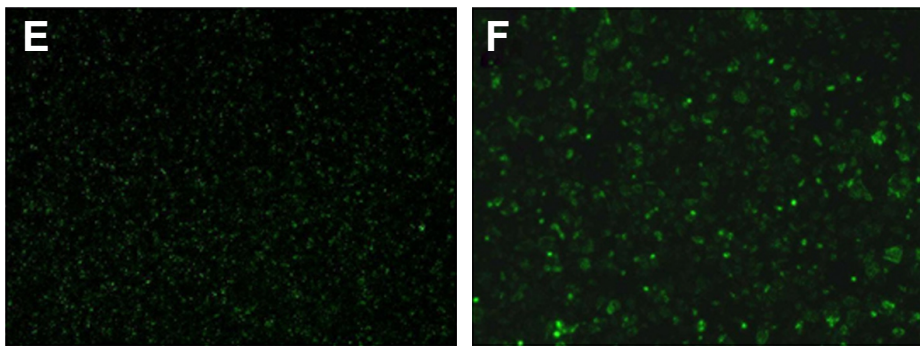

PRP + ASA

Figure 4 Immunofluorescence microscopy. Effects of TRAP and ASA on platelet aggregation. Immunofluorescence microscopy of platelet microaggregates in the presence or absence of TRAP and ASA. Staining was performed with fluorescent-labelled antibodies against activated GPIlb/llla (PAC-I).

Notes: (A, B) Platelet microaggregates in the absence of pharmacological agents. (C, D) Platelet microaggregates in the presence of TRAP. (E, F) Platelet microaggregates in the presence of ASA.

Abbreviations: ASA, acetylsalicylic acid; PRP, platelet-rich plasma; TRAP, thrombin receptor-activating peptide.

(apyrase $D \mathrm{p}=0.224$; apyrase $f \mathrm{p}=0.874$ and 2 -MeSAMP $D \mathrm{p}=0.3005 ; 2-M e S A M P f \mathrm{p}=0.2198, \mathrm{n}=4)$.

Since nitric oxide (NO) mediates major inhibitor pathways and regulates platelet GPIIb/IIIa receptor function, ${ }^{26-28}$ we tested the effects of platelet-inhibitory NO-releasing agents such as $\mathrm{SNAP}^{29}$ and GSNO. ${ }^{30}$ Both compounds inhibited platelet aggregation, as reflected by reduced changes in $f$ and $D$ compared with the control and corroborated by optical microscopy (SNAP $D \mathrm{p}=0.0005$; SNAP $f \mathrm{p}=0.0011$ and GNSO $D \mathrm{p}=0.0005 ; \mathrm{p}=0.0017, \mathrm{n}=4)$.

Finally, because prostacyclin is the most potent endogenous inhibitor of platelet aggregation and stimulator of disaggregation, ${ }^{31,32}$ its ability to induce disaggregation was also tested. Prostacyclin was able to reverse changes in $f$ and $D$, as shown in Figure 5.

\section{Characterization of NPs}

The size of polystyrene and silica NPs as measured by dynamic light scattering and helium ion scanning microscopy was in agreement with the manufacturer's specifications.

\section{Effects of NPs on platelet aggregation as measured by light aggregometry}

Incubation of PRP with $10 \mathrm{~nm}$ silica NPs $(25 \mu \mathrm{g} / \mathrm{mL})$, $50 \mathrm{~nm}$ silica NPs $(200 \mu \mathrm{g} / \mathrm{mL})$ and $23 \mathrm{~nm}$ polystyrene NPs $(100 \mu \mathrm{g} / \mathrm{mL})$ did not induce platelet aggregation as measured by the light aggregometer. However, as expected, incubation of platelets with the classical platelet aggregation agonist collagen $(5 \mu \mathrm{g} / \mathrm{mL})$ resulted in platelet aggregation (Figure 6).

\section{Effects of NPs on platelet microaggregation as measured by QCM-D and microscopy} Incubation of platelets with $10 \mathrm{~nm}$ silica NPs $(25 \mu \mathrm{g} / \mathrm{mL})$, $50 \mathrm{~nm}$ silica NPs $(200 \mu \mathrm{g} / \mathrm{mL})$, and $23 \mathrm{~nm}$ polystyrene NPs $(100 \mu \mathrm{g} / \mathrm{mL})$ induced significant changes in $f$ and in $D$ as compared with controls. These effects were confirmed by optical microscopy, which showed the presence of larger platelet aggregates on the surface of the crystals after perfusion of PRP in the presence of the NPs (Figures 7-9). 

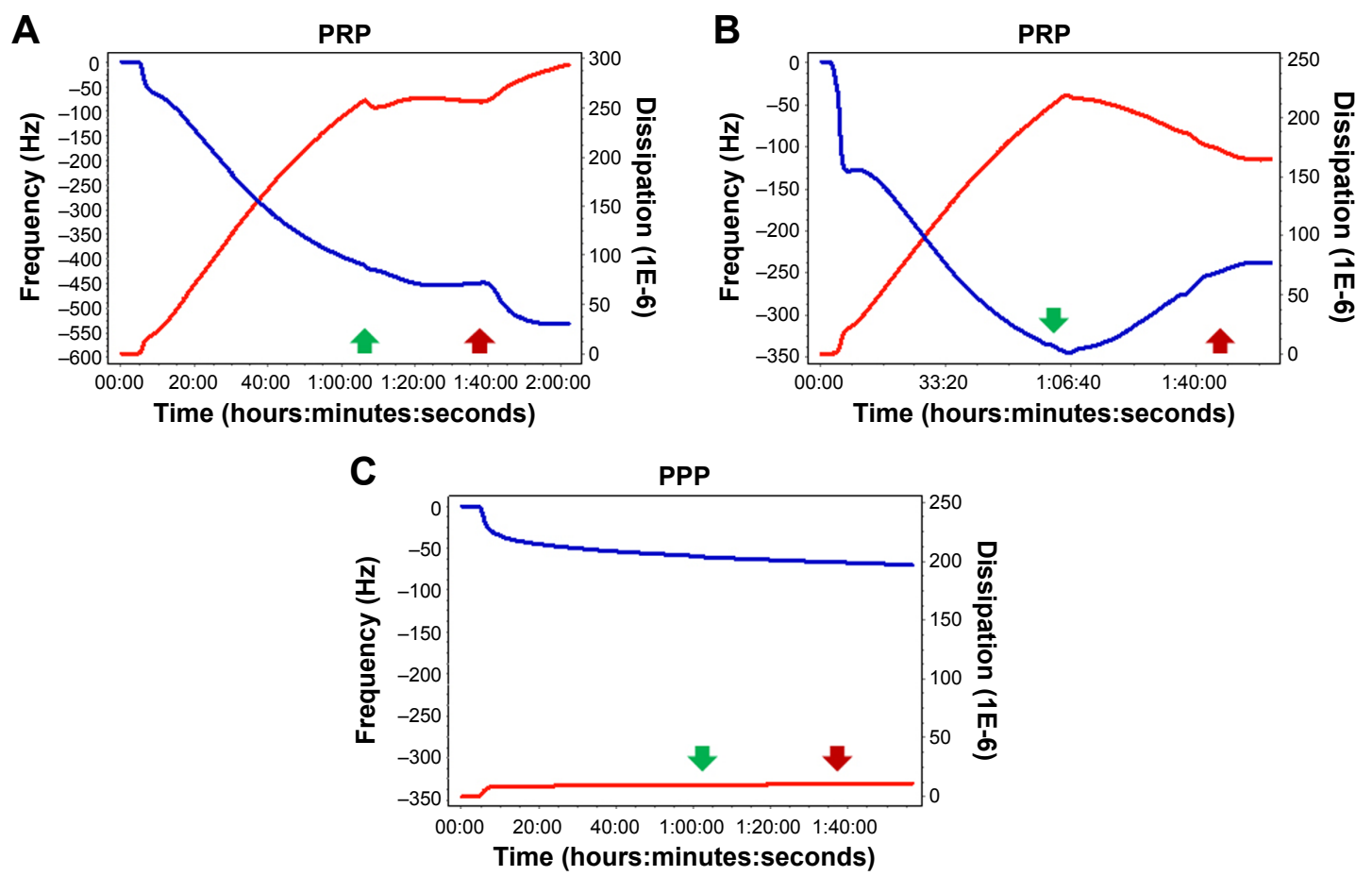

Figure 5 Quartz crystal microbalance with dissipation. Prostacyclin-mediated inhibition of platelet activation.

Notes: Prostacyclin inhibited $(\mathbf{A})$ and reversed $(\mathbf{B})$ platelet microaggregation on $f$ (blue line) and $D$ (red line). As expected, prostacyclin exerted no significant effects on accumulation of plasma proteins on the sensor surface (C). Green arrows indicate "prostacyclin on" and red arrows indicate "prostacyclin off".

Abbreviations: PRP, platelet-rich plasma; PPP, platelet-poor plasma.
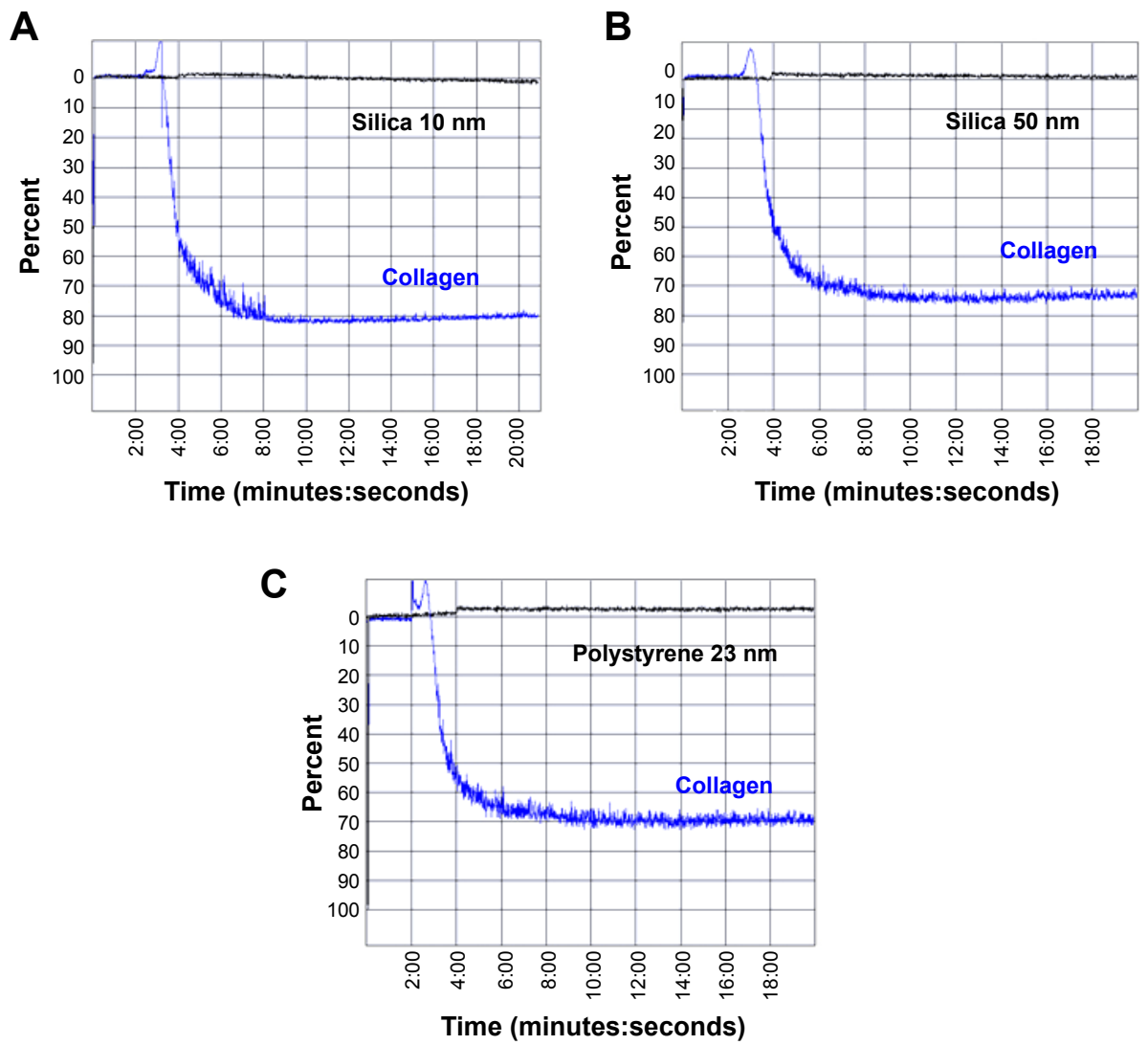

Figure 6 Light aggregometry. Effects of nanoparticles on platelet aggregation.

Notes: Incubation of PRP with (A) $10 \mathrm{~nm}$ silica nanoparticles $(25 \mu \mathrm{g} / \mathrm{mL})$, (B) $50 \mathrm{~nm}$ silica nanoparticles $(200 \mu \mathrm{g} / \mathrm{mL})$, and $(\mathbf{C}) 23 \mathrm{~nm}$ polystyrene nanoparticles (I00 $\mu \mathrm{g} / \mathrm{mL})$ did not induce platelet aggregation (black curves). Incubation of platelets with collagen $(5 \mu \mathrm{g} / \mathrm{mL}$ ) was used as the positive control (blue curve). 
A

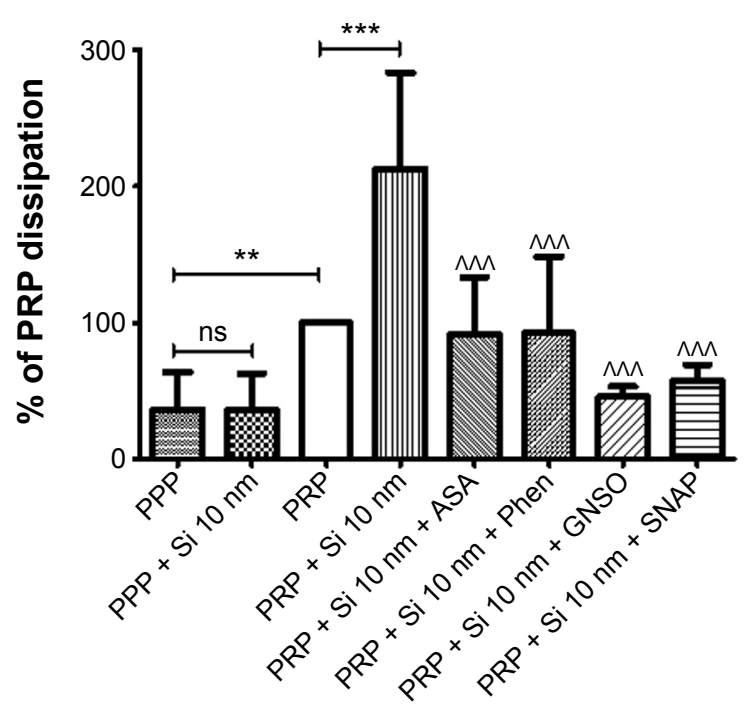

B

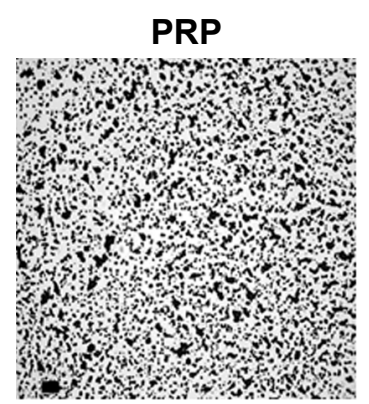

Silica $10 \mathrm{~nm}$

PRP + GNSO

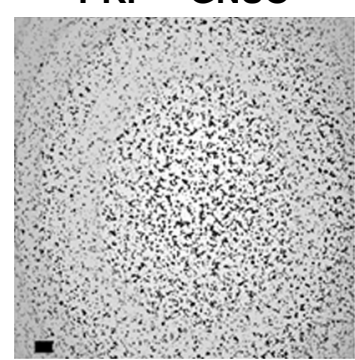

\section{Silica $10 \mathrm{~nm}$}
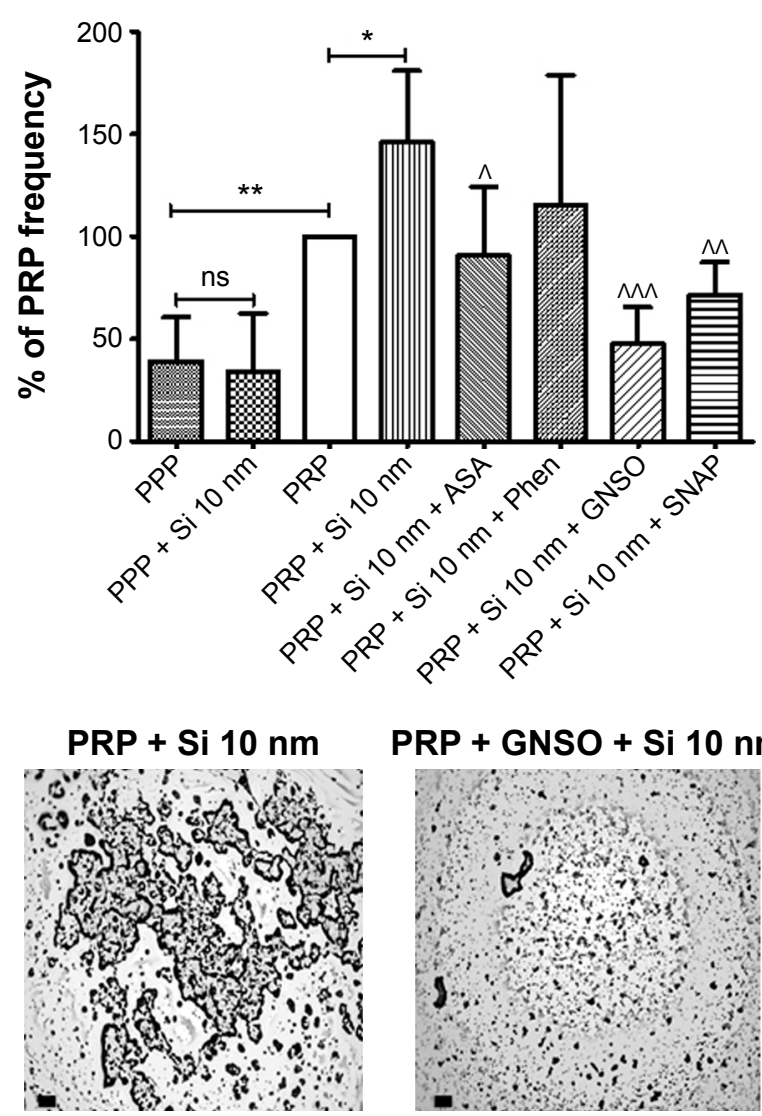

\section{PRP + GNSO + Si 10 nm}

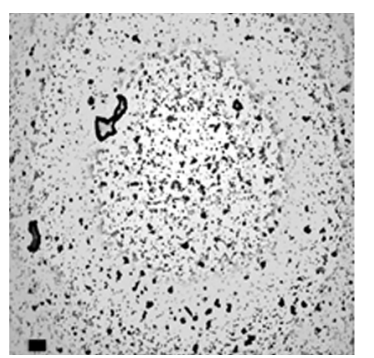

Figure 7 Quartz crystal microbalance with dissipation. Effects of $10 \mathrm{~nm}$ silica nanoparticles on platelet aggregation.

Notes: (A) Quantitative analysis of the effects of perfusion of PPP and PRP in the presence or absence of $10 \mathrm{~nm}$ silica nanoparticles and modulators of platelet function on frequency and energy dissipation. The data are presented as the mean \pm standard deviation. $* P<0.05,{ }^{*} * P<0.01,{ }^{* * * * P}<0.00$ I versus $P R P$. ${ }^{\wedge} P<0.05,{ }^{\wedge} P<0.01$, ${ }^{\wedge \wedge} P<0.00$ I versus PRP $+10 \mathrm{~nm}$ silica nanoparticles. (B) Representative micrographs of the surface of fibrinogen-coated PC-quartz crystals as viewed by optical microscopy showing platelet microaggregates following perfusion with PRP in the absence and presence of $10 \mathrm{~nm}$ silica nanoparticles and GSNO as an example of a pharmacological modulator of platelet function. Scale bar $20 \mu \mathrm{m}$.

Abbreviations: PRP, platelet-rich plasma; PPP, platelet-poor plasma; PC, polystyrene-coated; ASA, acetylsalicylic acid; Phen, phenanthroline; GSNO, S-nitroso-glutathione; $\mathrm{Si}$, silica; SNAP, S-nitroso-N-acetyl-DL-penicillamine.

In order to know if NPs were able to induce changes in $f$ and in $D$ in the absence of platelets, PPP in the absence or presence of silica NPs and polystyrene NPs were also perfused through the crystals. No significant changes were found in $f$ and in $D$ when PPP was incubated with the NPs (Figures 7-9).

\section{Pharmacological modulation of NP-induced platelet microaggregation: role of mediators and signaling pathways}

Knowing that ASA, phenanthroline, GSNO, and SNAP were able to significantly reduce fibrinogen-induced platelet microaggregation, we tested these compounds on NP-induced platelet microaggregation. We studied the effects of ASA, the most commonly used antiplatelet drug, which inhibits generation of thromboxane $\mathrm{A}_{2}\left(\mathrm{TXA}_{2}\right)$ in platelets, on microaggregation induced by NPs. ASA reduced the microaggregation induced by $10 \mathrm{~nm}$ silica, $50 \mathrm{~nm}$ silica, and $23 \mathrm{~nm}$ polystyrene NPs, as detected by changes in both $f$ and $D$ (Figures 7-9). We also tested the effect of phenanthroline, which inhibits the MMP-dependent pathway of aggregation, on NP-induced microaggregation. We found that phenanthroline failed to modify $f$ on microaggregation induced by $10 \mathrm{~nm}$ silica NPs. In contrast, the same concentration of phenanthroline was able to reduce microaggregation induced by $50 \mathrm{~nm}$ silica and $23 \mathrm{~nm}$ polystyrene NPs, as shown by changes in both $f$ and $D$ (Figures 7-9). Finally, we investigated the effects of GSNO and SNAP, two platelet-inhibitory NO-releasing agents, on NP-induced platelet microaggregation. Both inhibitors reduced NP-induced microaggregation as measured by changes in $f$ and $D$ induced by all three NPs tested (Figures 7-9). 

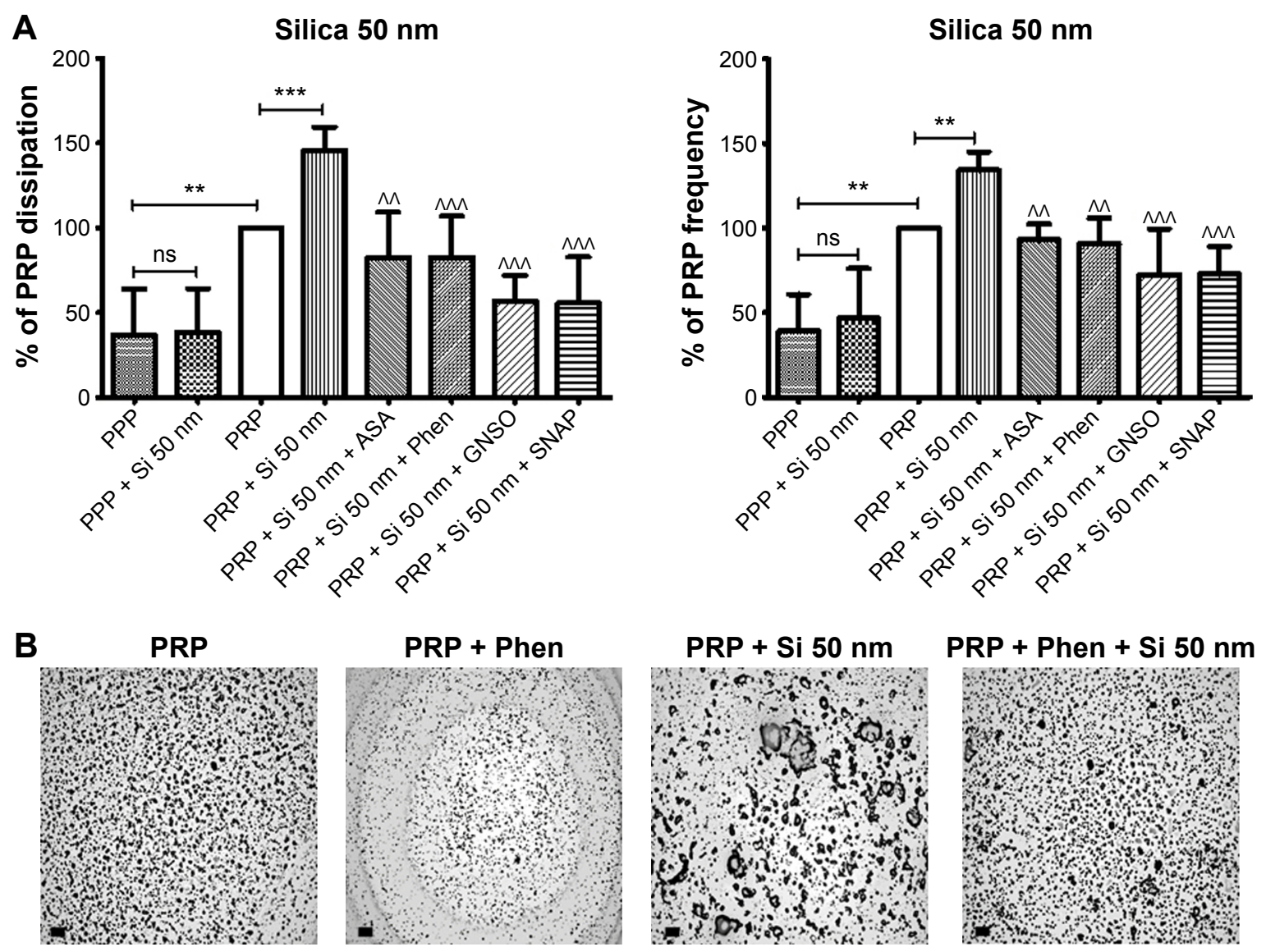

Figure 8 Quartz crystal microbalance with dissipation. Effects of $50 \mathrm{~nm}$ silica nanoparticles on platelet microaggregation.

Notes: (A) Quantitative analysis of the effects of perfusion of PPP and PRP in the presence or absence of $50 \mathrm{~nm}$ silica nanoparticles and modulators of platelet function on frequency and energy dissipation. The data are presented as the mean \pm standard deviation. ${ }^{* * P} P<0.01$; $* * * P<0.001$ versus $P R P$. ${ }^{\wedge} P<0.0$ I; ${ }^{\wedge} P<0.00$ I versus $P R P+50 \mathrm{~nm}$ silica nanoparticles. (B) Representative micrographs of the surface of fibrinogen-coated polystyrene-quartz crystals as viewed by optical microscopy showing platelet microaggregates following perfusion with PRP in the absence and presence of $50 \mathrm{~nm}$ silica nanoparticles and Phen as an example of a pharmacological modulator of platelet function. Scale bar $20 \mu \mathrm{m}$.

Abbreviations: PRP, platelet-rich plasma; PPP, platelet-poor plasma; ASA, acetylsalicylic acid; Phen, phenanthroline; GSNO, S-nitroso-glutathione; Si, silica; SNAP, S-nitroso$\mathrm{N}$-acetyl-DL-penicillamine.

\section{Discussion}

Platelet activation and aggregation play an important role in the pathophysiology of cardiovascular diseases, such as stroke and myocardial infarction. It has been previously shown that environmental exposure to air containing NPs is associated with a high incidence of cardiorespiratory morbidity and mortality ${ }^{33,34}$ and that engineered NPs may trigger platelet activation and aggregation in vitro ${ }^{8,9,15}$ and thrombus formation in vivo. ${ }^{8}$ Indeed, most of the research published in the nanotechnology-platelet field is focused on understanding and investigating the mechanisms involved in platelet-NP interactions. ${ }^{10}$ However, in some cases, these mechanisms are not very well characterized. This could be partly due to the standard use of non-flow devices in research for testing platelet function. In fact, there is widespread recognition of the need for more sensitive methods to test platelet function under flow conditions and in nanoscale. ${ }^{35}$ In the current study, we provide evidence that QCM-D is an appropriate device for preclinical evaluation of the biocompatibility of nanomaterials with platelets and for measuring the effects of standard pharmacological regulators on agonist-induced and NP-induced microaggregations.

\section{Pharmacology of fibrinogen-induced platelet microaggregation}

First, we ascertained that the QCM-D was able to detect changes in platelet microaggregation induced by standard platelet-modulating agents. TRAP is a potent proteinaseactivated receptor agonist that activates proteinase-activated receptor 1 (PAR1) and downstream the ADP-dependent, $\mathrm{TXA}_{2}$-dependent, and MMP-2-dependent aggregation pathways. ${ }^{36} \mathrm{We}$ found that TRAP amplified platelet microaggregation as monitored by QCM-D and this was corroborated by microscopy. Next, we studied the pharmacological effects of 
A
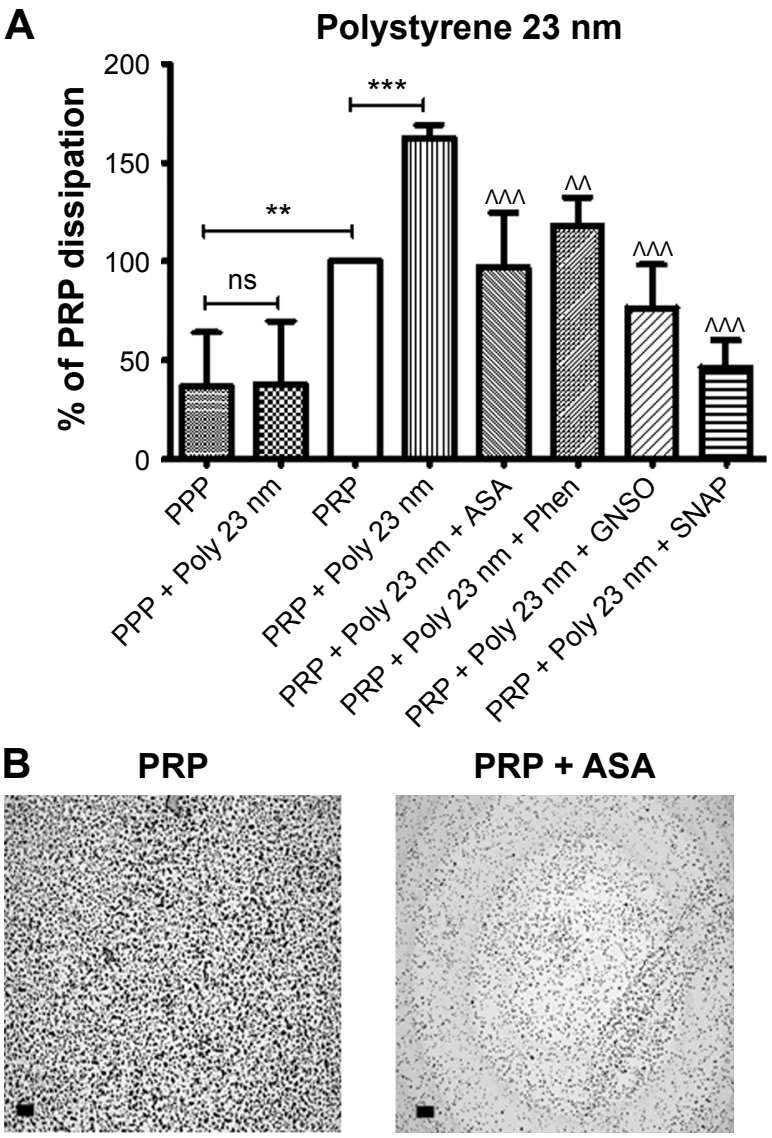

\section{PRP + ASA}

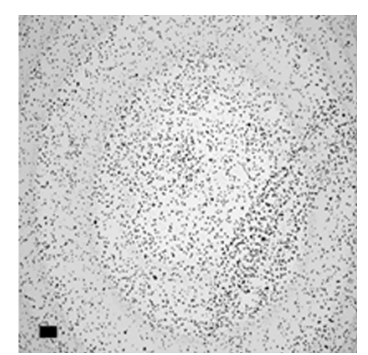

Polystyrene $23 \mathrm{~nm}$

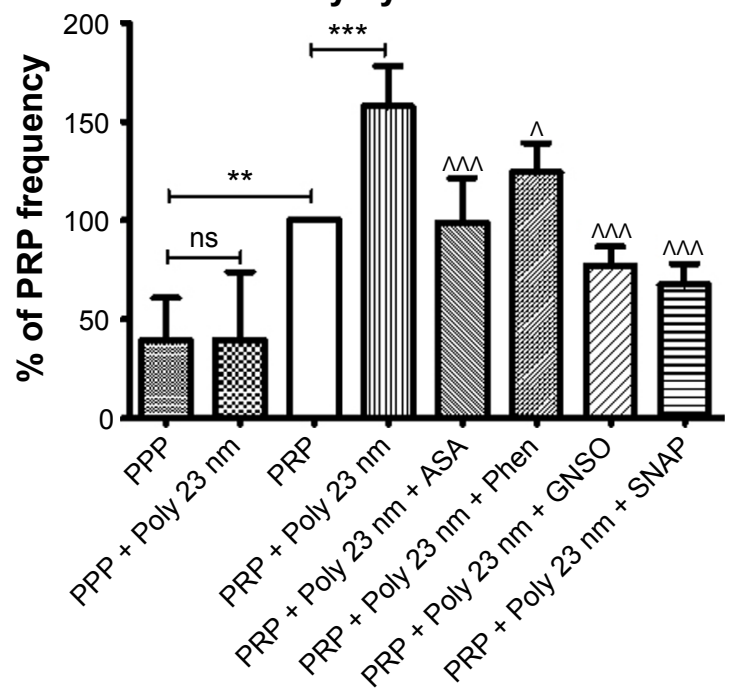

PRP + Poly 23 nm

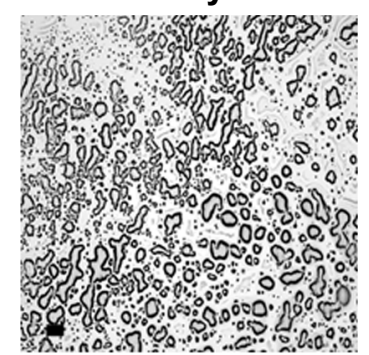

PRP + ASA + Poly $23 \mathrm{~nm}$

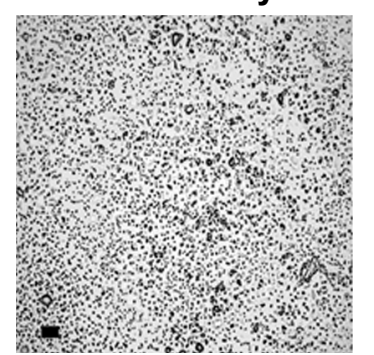

Figure 9 Quartz crystal microbalance with dissipation. Effects of $23 \mathrm{~nm}$ polystyrene nanoparticles on platelet microaggregation.

Notes: (A) Quantitative analysis of the effects of perfusion of PPP and PRP in the presence or absence of $23 \mathrm{~nm}$ polystyrene nanoparticles and modulators of platelet function on frequency and energy dissipation. The data are presented as the mean \pm standard deviation. ${ }^{* *} P<0.01$; ${ }^{* * *} P<0.001$ versus $P R P$. ${ }^{\wedge} P<0.05 ;{ }^{\wedge} P<0.01$; ${ }^{\wedge \wedge} P<0.001$ versus PRP $+23 \mathrm{~nm}$ polystyrene nanoparticles. (B) Representative micrographs of the surface of fibrinogen-coated polystyrene-quartz crystals as viewed by optical microscopy showing platelet aggregates following perfusion with PRP in the absence and presence of $23 \mathrm{~nm}$ polystyrene nanoparticles and ASA as an example of a pharmacological modulator of platelet function. Scale bar $20 \mu \mathrm{m}$.

Abbreviations: PRP, platelet-rich plasma; PPP, platelet-poor plasma; ASA, acetylsalicylic acid; Phen, phenanthroline; GSNO, S-nitroso-glutathione; Si, silica; SNAP, S-nitroso$\mathrm{N}$-acetyl-DL-penicillamine; Poly, polystyrene.

a panel of platelet inhibitors in order to evaluate the relative contributions of the $\mathrm{TXA}_{2}$-dependent, MMP-2-dependent, and ADP-dependent pathways to platelet microaggregation. We found that both ASA and phenanthroline were able to inhibit platelet aggregation, showing the involvement of $\mathrm{TXA}_{2}$ and MMP-2 in this process. However, apyrase and 2-MeSAMP did not exert significant effects on platelet microaggregation, indicating that release of ADP from platelets does not significantly contribute to generation of platelet microaggregates under the experimental conditions used. Prostacyclin and NO are important platelet inhibitors generated from the endothelium that synergize to regulate platelet activation; ${ }^{31}$ therefore, prostacyclin and two NOreleasing compounds, GSNO and SNAP, known to inhibit platelet aggregation, ${ }^{29,30}$ were also tested. Prostacyclin was not only able to inhibit platelet aggregation but also caused disaggregation as monitored in real-time by the device, an effect similar to that measured by light aggregometry. ${ }^{27}$ We also found that GSNO and SNAP inhibited platelet microaggregation as measured by the device and corroborated this effect by phase-contrast microscopy. Taken together, our results show that the QCM-D method is able to detect changes in platelet microaggregation induced by standard platelet-modulating agents.

\section{Pharmacology of NP-induced platelet microaggregation}

Silica NPs and polystyrene NPs were selected to study the effects of NPs on platelets because they are widely used in industrial and pharmacological applications. ${ }^{37,38}$ In order to corroborate the NP characteristics as specified by their manufacturer, their size was evaluated prior to pharmacological studies. The measurements showed that the NPs did not diverge from the manufacturer's specifications. This is 
extremely important when evaluating the toxicological effects of NPs on biological systems, given that agglomeration of NPs could, among other effects, influence cellular uptake $^{39}$ and generation of reactive oxygen species. ${ }^{40}$

Next, we studied the effects of silica NPs and polystyrene NPs on platelet aggregation using light aggregometry. Importantly, none of the evaluated NPs, at the concentrations tested, induced platelet aggregation in PRP, which is in agreement with our previous study. ${ }^{15}$ However, light aggregometry was capable of measuring platelet aggregation induced by collagen, and showed that platelets reacted as expected in the presence of a standard platelet stimulant. In contrast, the QCM-D was able to detect platelet microaggregation induced by all three types of NPs at concentrations undetectable by light aggregometry. Interestingly, when the silica NPs were compared, the smaller NPs (10 $\mathrm{nm})$ induced more platelet microaggregation than the larger NPs $(50 \mathrm{~nm})$, as measured by changes in $D$. These results were corroborated by phase-contrast microscopy and are in good agreement with our previous studies. ${ }^{9,14,15}$ Importantly, because QMC-D is a very sensitive device and can detect nanograms of mass, it was investigated whether or not all three NPs on their own or via interactions with plasma proteins $^{41}$ could be responsible for changes in $f$ and $D$. However, we did not find changes in $f$ or $D$ when PPP was allowed to interact with NPs as compared with NP-free PPP, indicating that the changes in $f$ and $D$ were due to platelet but not NP deposition.

We then investigated whether NP-induced platelet microaggregation could be inhibited by the NO donors, phenanthroline and ASA. Platelet microaggregation induced by all NPs tested was inhibited by GSNO and SNAP, indicating that platelets exposed to NPs retain their ability to be regulated by pharmacological inhibitors of platelet activation. In fact, NO is generated by the endothelium and has the ability to maintain vasodilator tone and inhibit platelet function via stimulation of the soluble guanylate cyclase and cGMP-induced reduction in intracellular calcium levels. ${ }^{28,42}$ Recently, we reviewed the mechanisms involved in platelet-NP interactions and proposed that increased intraplatelet calcium levels contribute to NP-induced platelet aggregation. ${ }^{10}$ In contrast, decreased NO bioactivity may play a role in the pathogenesis of atherosclerosis and ischemic heart disease. ${ }^{43}$

Phenanthroline, an inhibitor of the MMP-2-mediated pathway of platelet aggregation ${ }^{23}$ exerted differential effects on NP-induced platelet microaggregation by inhibiting reactions stimulated by polystyrene NPs and $50 \mathrm{~nm}$ silica NPs, but not those induced by $10 \mathrm{~nm}$ silica NPs. Indeed, phenanthroline failed to induce significant changes in $f$ when $10 \mathrm{~nm}$ silica NPs were allowed to interact with platelets. This could be explained by the fact that formation of large aggregates by smaller NPs, such as $10 \mathrm{~nm}$ silica NPs, is more accurately detected by changes in $D .^{12}$ In fact, we have previously found that the smallest silica NPs induced the most severe effects on washed platelets. ${ }^{9}$ In addition, their shape and surface characteristics (electrochemical charge and redox properties) are further considerations. ${ }^{10}$

In the current experiments, ASA, a classical inhibitor of cyclooxygenase and the $\mathrm{TXA}_{2}$-dependent pathway of platelet aggregation and one of the drugs most frequently used to prevent thrombotic complications of vascular atherosclerosis, ${ }^{44}$ inhibited silica and polystyrene NP-induced platelet microaggregation. Interestingly, ASA had no significant impact on carbon NP-induced aggregation, ${ }^{8}$ suggesting differential involvement of TXA $\mathrm{T}_{2}$ in the effects mediated by various NPs.

What is the significance of our study? First, we demonstrated that QCM-D, but not light aggregometry, is a very sensitive tool for detection of NP-induced platelet aggregation. In fact, our method detects nanograms of mass, and therefore platelet microaggregation, while light aggregometry does not. This is very important when studying $\mathrm{NP}$-platelet interactions, given that platelet microaggregates produced in the early phases of platelet activation are now considered to potentially aggravate thrombus formation. ${ }^{5,45}$ Second, we provide evidence that NP-induced platelet microaggregation is amenable to pharmacological modulation by inhibitors of two major pathways of aggregation that are mediated via generation of $\mathrm{TXA}_{2}$ and MMP-2. In contrast, release of ADP from platelets is likely to be low under the conditions used because ADP blockers do not modify platelet microaggregation.

Finally, our study provides further evidence that preclinical evaluation of the effect of NPs on platelet function should be considered as an essential step to ensure their design as non-toxic agents with optimum platelet compatibility. ${ }^{10}$

\section{Acknowledgments}

The work was supported by a Science Foundation Ireland (SFI) principal investigator grant to MWR (S.F.I.O5/FE1/B862) and SFI-RFP grant (RFP/BMT2781) to CM. CM is an SFI Stokes lecturer. MJSM is an Ussher lecturer in Nanopharmaceutical Drug Discovery at Trinity College Dublin. KAT received funding from the Jagiellonian University Medical College statutory funds for young scientists. The authors would like to acknowledge Heath Bagshaw and Neal Leddy 
(Centre for Microscopy and Analysis) for their assistance with the scanning electron microscopy and Esther Rufino for technical assistance.

\section{Disclosure}

The authors report no conflicts of interest in this work.

\section{References}

1. Parveen S, Misra R, Sahoo SK. Nanoparticles: a boon to drug delivery, therapeutics, diagnostics and imaging. Nanomedicine. 2012;8(2): $147-166$.

2. Khan IU, Serra CA, Anton N, Vandamme TF. Production of nanoparticle drug delivery systems with microfluidics tools. Expert Opin Drug Deliv. 2015;12(4):547-562.

3. Davì G, Patrono C. Platelet activation and atherothrombosis. $N$ Engl J Med. 2007;357(24):2482-2494.

4. Linden MD, Jackson DE. Platelets: pleiotropic roles in atherogenesis and atherothrombosis. Int J Biochem Cell Biol. 2010;42(11):1762-1766.

5. Ruggeri ZM. Platelets in atherothrombosis. Nat Med. 2002;8(11): 1227-1234.

6. Antithrombotic Trialists' Collaboration. Collaborative meta-analysis of randomised trials of antiplatelet therapy for prevention of death, myocardial infarction, and stroke in high risk patients. BMJ. 2002;324(7329):71-86.

7. Maree AO, Fitzgerald DJ. Variable platelet response to aspirin and clopidogrel in atherothrombotic disease. Circulation. 2007;115(16): 2196-2207.

8. Radomski A, Jurasz P, Alonso-Escolano D, et al. Nanoparticle-induced platelet aggregation and vascular thrombosis. Br J Pharmacol. 2005; 146(6):882-893

9. Corbalan JJ, Medina C, Jacoby A, Malinski T, Radomski MW. Amorphous silica nanoparticles aggregate human platelets: potential implications for vascular homeostasis. Int J Nanomedicine. 2012;7:631-639.

10. Tomaszewski KA, Radomski MW, Santos-Martinez MJ. Nanodiagnostics, nanopharmacology and nanotoxicology of platelet-vessel wall interactions. Nanomedicine (Lond). 2015;10(9):1451-1475.

11. Medina C, Santos-Martinez MJ, Radomski A, Corrigan OI, Radomski MW. Nanoparticles: pharmacological and toxicological significance. Br J Pharmacol. 2007;150(5):552-558.

12. Santos-Martinez MJ. A novel method for the measurement of flowinduced platelet activation at nanoscale resolution level. $\mathrm{PhD}$ thesis. Dublin, Ireland: Trinity College Dublin; 2009.

13. Santos-Martínez MJ, Medina C, Prina-Mello A, et al. A nanoscale resolution assay of flow-induced platelet microaggregation. Kardiochir Torakochi. 2010;7(4):365-375.

14. Santos-Martinez MJ, Rahme K, Corbalan JJ, et al. Pegylation increases platelet biocompatibility of gold nanoparticles. J Biomed Nanotechnol. 2014;10(6):1004-1015.

15. Santos-Martinez MJ, Inkielewicz-Stepniak I, Medina C, et al. The use of quartz crystal microbalance with dissipation (QCM-D) for studying nanoparticle-induced platelet aggregation. Int J Nanomedicine. 2012; 7:243-255.

16. Lordkipanidzé M, Pharand C, Schampaert E, Turgeon J, Palisaitis DA, Diodati JG. A comparison of six major platelet function tests to determine the prevalence of aspirin resistance in patients with stable coronary artery disease. Eur Heart J. 2007;28(14):1702-1708.

17. Radomski M, Moncada S. An improved method for washing of human platelets with prostacyclin. Thromb Res. 1983;30(4):383-389.

18. Medina C, Jurasz P, Santos-Martinez MJ, et al. Platelet aggregationinduced by Caco- 2 cells: regulation by matrix metalloproteinase- 2 and adenosine diphosphate. J Pharmacol Exp Ther. 2006;317(2): 739-745.

19. Alonso-Escolano D, Strongin AY, Chung AW, Deryugina EI, Radomski MW. Membrane type-1 matrix metalloproteinase stimulates tumour cell-induced platelet aggregation: role of receptor glycoproteins. Br J Pharmacol. 2004;141(2):241-252.
20. Jurasz P, Sawicki G, Duszyk M, et al. Matrix metalloproteinase 2 in tumor cell-induced platelet aggregation: regulation by nitric oxide. Cancer Res. 2001;61(1):376-382.

21. Roth GJ, Majerus PW. The mechanism of the effect of aspirin on human platelets. I. Acetylation of a particulate fraction protein. J Clin Invest. 1975;56(3):624-632.

22. Vane J. Inhibition of prostaglandin synthesis as a mechanism of action for aspirin-like drugs. Nat New Biol. 1971;231(25):232-235.

23. Sawicki G, Salas E, Murat J, Miszta-Lane H, Radomski MW. Release of gelatinase A during platelet activation mediates aggregation. Nature. 1997;386(6625):616-619.

24. Santos-Martinez MJ, Medina C, Jurasz P, Radomski MW. Role of metalloproteinases in platelet function. Thromb Res. 2008;121(4): 535-542.

25. Cohn M, Meek GA. The mechanism of hydrolysis of adenosine di- and tri-phosphate catalysed by potato apyrase. Biochem J. 1957;66(1): 128-130.

26. Radomski MW, Palmer RM, Moncada S. Endogenous nitric oxide inhibits human platelet adhesion to vascular endothelium. Lancet. 1987; 2(8567):1057-1058.

27. Radomski MW, Palmer RM, Moncada S. Comparative pharmacology of endothelium-derived relaxing factor, nitric oxide and prostacyclin in platelets. Br J Pharmacol. 1987;92(1):181-187.

28. Radomski MW, Palmer RM, Moncada S. An L-arginine/nitric oxide pathway present in human platelets regulates aggregation. Proc Natl Acad Sci U S A. 1990;87(13):5193-5197.

29. Salas E, Moro MA, Askew S, et al. Comparative pharmacology of analogues of S-nitroso-N-acetyl-DL-penicillamine on human platelets. Br J Pharmacol. 1994;112(4):1071-1076.

30. Radomski MW, Rees DD, Dutra A, Moncada S. S-nitroso-glutathione inhibits platelet activation in vitro and in vivo. Br J Pharmacol. 1992; 107(3):745-749.

31. Radomski MW, Palmer RM, Moncada S. The anti-aggregating properties of vascular endothelium: interactions between prostacyclin and nitric oxide. Br J Pharmacol. 1987;92(3):639-646.

32. Moncada S, Gryglewski RJ, Bunting J, Vane JR. An enzyme isolated from arteries transforms prostaglandin endoperoxides to an unstable substance that inhibits platelet aggregation. Nature. 1976;263(5579): 663-665.

33. Nemmar A, Hoet PH, Vanquickenborne B, et al. Passage of inhaled particles into the blood circulation in humans. Circulation. 2002;105(4): 411-414.

34. Nemmar A, Hoylaerts MF, Hoet PH, Nemery B. Possible mechanisms of the cardiovascular effects of inhaled particles: systemic translocation and prothrombotic effects. Toxicol Lett. 2004;149(1-3):243-253.

35. Santos-Martinez M, Prina-Mello A, Medina C, Radomski M. Analysis of platelet function: role of microfluidics and nanodevices. Analyst. 2011; 136(24):5120-5126.

36. Chung AW, Radomski A, Alonso-Escolano D, et al. Platelet-leukocyte aggregation induced by PAR agonists: regulation by nitric oxide and matrix metalloproteinases. Br J Pharmacol. 2004;143(7):845-855.

37. Slowing II, Vivero-Escoto JL, Wu C-W, Lin VS. Mesoporous silica nanoparticles as controlled release drug delivery and gene transfection carriers. Adv Drug Deliv Rev. 2008;60(11):1278-1288.

38. Youssef AM, Kamel S, El-Samahy MA. Morphological and antibacterial properties of modified paper by PS nanocomposites for packaging applications. Carbohydr Polym. 2013;98(1):1166-1172.

39. Gliga A, Skoglund S, Odnevall Wallinder I, Fadeel B, Karlsson H. Size-dependent cytotoxicity of silver nanoparticles in human lung cells: the role of cellular uptake, agglomeration and Ag release. Part Fibre Toxicol. 2014;11(1):11.

40. Park E-J, Choi J, Park Y-K, Park K. Oxidative stress induced by cerium oxide nanoparticles in cultured BEAS-2B cells. Toxicology. 2008; 245(1-2):90-100.

41. Lesniak A, Salvati A, Santos-Martinez MJ, Radomski MW, Dawson KA, Åberg C. Nanoparticle adhesion to the cell membrane and its effect on nanoparticle uptake efficiency. J Am Chem Soc. 2013;135(4): $1438-1444$. 
42. Moro MA, Russel RJ, Cellek S, et al. cGMP mediates the vascular and platelet actions of nitric oxide: confirmation using an inhibitor of the soluble guanylyl cyclase. Proc Natl Acad Sci U S A. 1996;93(4): 1480-1485.

43. Egashira K. Clinical importance of endothelial function in arteriosclerosis and ischemic heart disease. Circ J. 2002;66(6):529-533.
44. Hennekens CH, Dalen JE. Aspirin in the treatment and prevention of cardiovascular disease: past and current perspectives and future directions. Am J Med. 2013;126(5):373-378.

45. Miyamoto S, Kawano H, Sakamoto T, et al. Formation of platelet microaggregates correlates with adverse clinical outcome in patients with coronary artery disease. Thromb Haemost. 2003;89(4):681-686.

\section{Publish your work in this journal}

The International Journal of Nanomedicine is an international, peerreviewed journal focusing on the application of nanotechnology in diagnostics, therapeutics, and drug delivery systems throughout the biomedical field. This journal is indexed on PubMed Central, MedLine, CAS, SciSearch ${ }^{\circledR}$, Current Contents ${ } /$ Clinical Medicine,
Journal Citation Reports/Science Edition, EMBase, Scopus and the Elsevier Bibliographic databases. The manuscript management system is completely online and includes a very quick and fair peer-review system, which is all easy to use. Visit http://www.dovepress.com/ testimonials.php to read real quotes from published authors.

Submit your manuscript here: http://www.dovepress.com/international-journal-of-nanomedicine-journal 